\title{
GIS-based biomass assessment and supply logistics system for a sustainable biorefinery: A case study with cotton stalks in the Southeastern US.
}

\author{
K. Sahoo ${ }^{a}$, G.L. Hawkins ${ }^{b}$, X.A. Yao ${ }^{c}$, K. Samples ${ }^{d}$, S. Mani ${ }^{a *}$ \\ ${ }^{a}$ College of Engineering, University of Georgia, Athens, GA 30602, USA \\ ${ }^{b}$ Department of Crop and Soil Science, University of Georgia, 30602, USA \\ ${ }^{c}$ Department of Geography, University of Georgia, Athens, GA 30602, USA \\ ${ }^{d}$ Natural Resources Spatial Analysis Laboratory (NARSAL), University of Georgia, Athens, GA 30602, \\ $U S A$
}

*Corresponding author, Ph: 706-542-2358; email:smani@engr.uga.edu

\begin{abstract}
Envisioning a sustainable biorefinery requires reliable information on the sustainable availability of biomass, optimal plant location and delivered cost. In this paper, we have developed an integrated Geographic Information System (GIS) based sustainable biomass assessment, site optimization and supply logistics cost model to assess the spatial and temporal availability of crop residues, to identify optimal plant sites and to calculate the delivered cost. The grid-level (30x30m) assessment model was developed for crop residues using three primary sustainability indicators: (1) Soil Erosion (SE), (2) Soil Conditioning Index (SCI) and (3) Crop residue yield $\geq 2.5$ dry $\mathrm{Mg} / \mathrm{ha}$. The Artificial Neural Networks (ANNs) prediction models for each indicator were developed and implemented in the GIS platform to estimate SE and SCI values to assess sustainably available crop residues. A multi-criteria geospatial analysis was used to identify suitable plant sites. GIS-based location-allocation model was used to site biorefineries/plants at optimal locations and generate feedstock supply curves. The developed model was demonstrated with the sustainable assessment of cotton stalk (CS) to produce fuel pellets in the study region (Georgia, USA). The model has estimated that about 1.6 million dry $\mathrm{Mg}$ of $\mathrm{CS}$ is available
\end{abstract}


annually to support seven pellet plants an average annual plant capacity of 200,000 dry $\mathrm{Mg}$. The average delivered cost of CS ranged between 68 and $75 \$ /$ dry Mg as large rectangular bales with the transport radii ranged from 31 to $60 \mathrm{~km}$. The spatial and temporal variations in the topology and crop yield directly influenced the sustainable availability of CS, the optimal plant location and its capacity and the delivered cost. However, the changes in the optimal plant location and delivered cost were minimal for large capacity plants (>400,000 dry $\mathrm{Mg}$ ). The developed model can be used to assess multiple crop residues, to manage and control feedstock supply risks and delivered cost variations for a sustainable biorefinery.

Keywords: Artificial Neural Network, soil erosion, soil conditioning index, geographical information system (GIS), location-allocation model, cotton stalk, delivered cost.

\section{Introduction}

Environmental degradation, climate change, and high energy demand have created a new market opportunity and interest to utilize lignocellulosic feedstocks such as agricultural crop residues and energy crops for bioenergy applications. Among all lignocellulosic feedstocks, agricultural crop residues are the largest sources of readily available biomass in the USA [1]. They have a potential to mitigate greenhouse gas (GHG) emissions if they can be sustainably harvested and. A sustainable biorefinery requires a consistent and risk-free supply of biomass delivered to a biorefinery without compromising the long-term soil health at low cost [2-5]. Therefore, a reliable and accurate assessment of sustainably available crop residues at the field/grid level is required to reduce biomass availability risks, to design optimal supply chain network and to suggest long-term policy decisions. The complete removal of crop residues caused increased soil erosion and decreased soil organic matter (SOM) accumulated in the soil, hence the loss of soil and its quality. Therefore, the residue removal rate (RRR) should be optimized for bioenergy applications while preserving the long-term productivity of croplands [7]. Wilhelm et al. [8] illustrated the sustainable removal of corn stover based on the SE and soil organic carbon (SOC) as limiting indicators for ten representative soil types in major corn growing states. Nelson [9] used the Revised Universal Soil 
Loss Equation (RUSLE2) and Wind Erosion Equation (WEQ) to assess the RRR for major crop types using county-level soil data. Later, this study was updated to calculate SE using land capability class (LCC) level data [10] for sustainable availability of crop residues. However, it was debated that the SE limit (T value) alone would not provide sufficient protection against soil quality and productivity loss [11, 12]. Graham et al. [13] estimated the county-level availability of corn stover considering the SE limit, the harvesting efficiency of stover, soil moisture as the limiting factors. However, the soil parameters used to estimate SE varied from one field to another and the county-level estimation of SE limit could be unreliable.

The Natural Resources Conservation Service (NRCS) in the US has developed a new sustainability indicator, the Soil Conditioning Index (SCI) to predict the long-term quality of soil at the field level [14]. The SCI value is a weighted average of a soil organic matter factor (40\%), soil erosion factor (20\%) and the field operation factor (40\%). The positive, negative and zero SCI values calculated for each field indicate accumulation, degradation, and maintenance of soil organic matter respectively [6, 15]. Muth et al. $[7,16]$ developed a highly reliable and comprehensive tool to estimate major crop residues at the soil polygon level using SE and SCI as sustainability indicators for large study area. However, the model was unable to accommodate sub-field level variations of crop yield, topographical and climatic properties that will directly influence the estimation of sustainability indicators and hence the variations in sustainable availability of biomass $[17,18]$. Also, the areas of soil polygons vary widely from less than one to more than 100 thousands of ha. Therefore, a realistic and farm/grid level estimation of SE and SCI values is critical for the accurate assessment of sustainably available crop residues. RUSLE2 is one of the widely used robust tools to estimate sustainability indicators for a uniform small area with location specific inputs (e.g. county, slope, slope length, crop yield, crop rotations, tillage types, crop management inputs, etc.) $[7,17]$. A unique combination of these inputs to the RUSLE2 tool is called a scenario. There can be millions or billions of such scenarios may exist at soil polygon level or even at grid level (30x30m) and will require huge computational time and computing resources to estimate sustainability indicators for a 
large study area [6]. Therefore, an efficient and reliable approach is necessary to quantify sustainable availability of crop residues accurately for a large study area without compromising the grid specific data such as soil properties, topography, climate data, crop yield and management practices.

The predictive models such as linear regression or artificial neural networks (ANNs) are often used to predict SE, soil and water quality indicators using site-specific input data [19-23]. These predictive models are simpler to implement and assess biomass availability efficiently for a large study area [21]. Furthermore, the predictability of these models is sometimes better than that of physical models [24]. GIS can handle very large data and provide modeling platform for efficient and reliable manipulation of data [25]. Therefore, predictive models can be imitated in the GIS platform for reliable prediction of sustainable removal of crop residues by capturing high-resolution spatial variabilities of input data.

The availability of agricultural residues varies both spatially and temporally and its accurate estimation and aggregation resolution are necessary, while configuring the optimal structure of a bioenergy supply chain [26]. The residue yield variations can significantly affect the harvesting cost and other sustainability indicators [27]. GIS is capable of handling high-resolution spatial data sets over a large area in order to automate data processing, develop analytical models, and improve graphical representations of relevant datasets $[28,29]$. The aggregation of biomass availability at a county level could pose a major risk to bioenergy stakeholders due to under or over estimation of feedstock availability, its delivered cost, and identification of optimal locations. For example, a regionally specific feedstock, Cotton Stalks (CS) was estimated at the State-level without considering sustainability indicators. But, CS is one of the dominant, harvestable crop residues that can be used to produce fuel pellets for bioenergy applications. At present, CS is mulched with soil or removed from the cropland to restrict future pest infestations. Economic collection and utilization of CS as a feedstock for bioenergy production can offer new incentives to cotton growers [30]. Therefore, the integration of sustainable assessment and supply logistics cost of biomass at a high spatial resolution is critical to reducing feedstock availability risks and delivered cost for a consistent supply of feedstock to a biorefinery. 
The selection of possible sites to locate plants for a large study area is a daunting task which can be realistically accomplished using geospatial analysis tools. The GIS-based multi-criteria suitability analysis is one of the most efficient approaches to selecting possible sites for potential biorefinery/pellet plant locations [31-33]. The selection of a plant location is often constrained by economic, social, geographical and legal factors. The Analytical Hierarchy Process (AHP) was the most dominant tool used in the bioenergy sector for locating possible plant sites. However, a large number of selection criteria and modeler's bias in weight selection could add subjectivity. The selection of limited critical criteria with similar weight could produce desirable results in identifying potential sites for establishing plants.

The optimized biomass supply chain can play a major role in the successful operation of sustainable bioenergy plants [31]. A GIS-based optimization model can provide the physical location of both supply (i.e. farms) and demand locations (i.e. plants), actual shortest road network distances, road diversion possibilities, and road characteristics like speed, traffic, etc. and such models can reduce the feedstock supply related risk barriers and cost variabilities for efficient risk management [34]. Previously, GISbased biomass assessment in combination with optimal plant location and logistics cost assessment was studied by Sultana \& Amit [32], Maung et al.[35] and Höhn et al. [33] without assessing the sustainable availability of crop residues. Furthermore, temporal variability of biomass availability and the farm gate cost has been neglected in these studies as they could significantly influence the decisions to identify best biorefinery sites, defining the plant capacity and estimating total logistics cost [32]. The farm-gate cost of harvested biomass varies widely and inversely with biomass yield [27]. For example, Sokhansanj et al. [36] reported that the farm-gate cost could be reduced by $20 \%$, when the biomass yield was increased by $33 \%$. A holistic, system-level modeling approach with high spatial resolution is critical to assess sustainable feedstock availability and to identify and optimize location-allocation for plant sites for designing a sustainable bioenergy supply chain.

The objectives of this study were: (i) to develop an integrated GIS and ANN prediction model at high spatial resolution to estimate sustainable availability of crop residues, (ii) to identify suitable 
biorefinery sites using GIS-based multi-criteria suitability analysis, and (iii) to select optimal sites (uncapacitated/capacitated) to minimize total transport distance using GIS-based location-allocation model along with the delivered cost.

\section{$2 \quad$ Methodology}

A conceptual framework of an integrated GIS-based modeling approach is shown in Figure 1. The sustainable availability of crop residues was estimated based on Soil Erosion (SE), Soil Conditioning Index (SCI) and economically harvestable residue yield data at a high spatial resolution of $30 \times 30 \mathrm{~m}$. The

proposed modeling approach was tested and demonstrated with Cotton Stalks (CS) as a model crop residue from the southeastern US. 


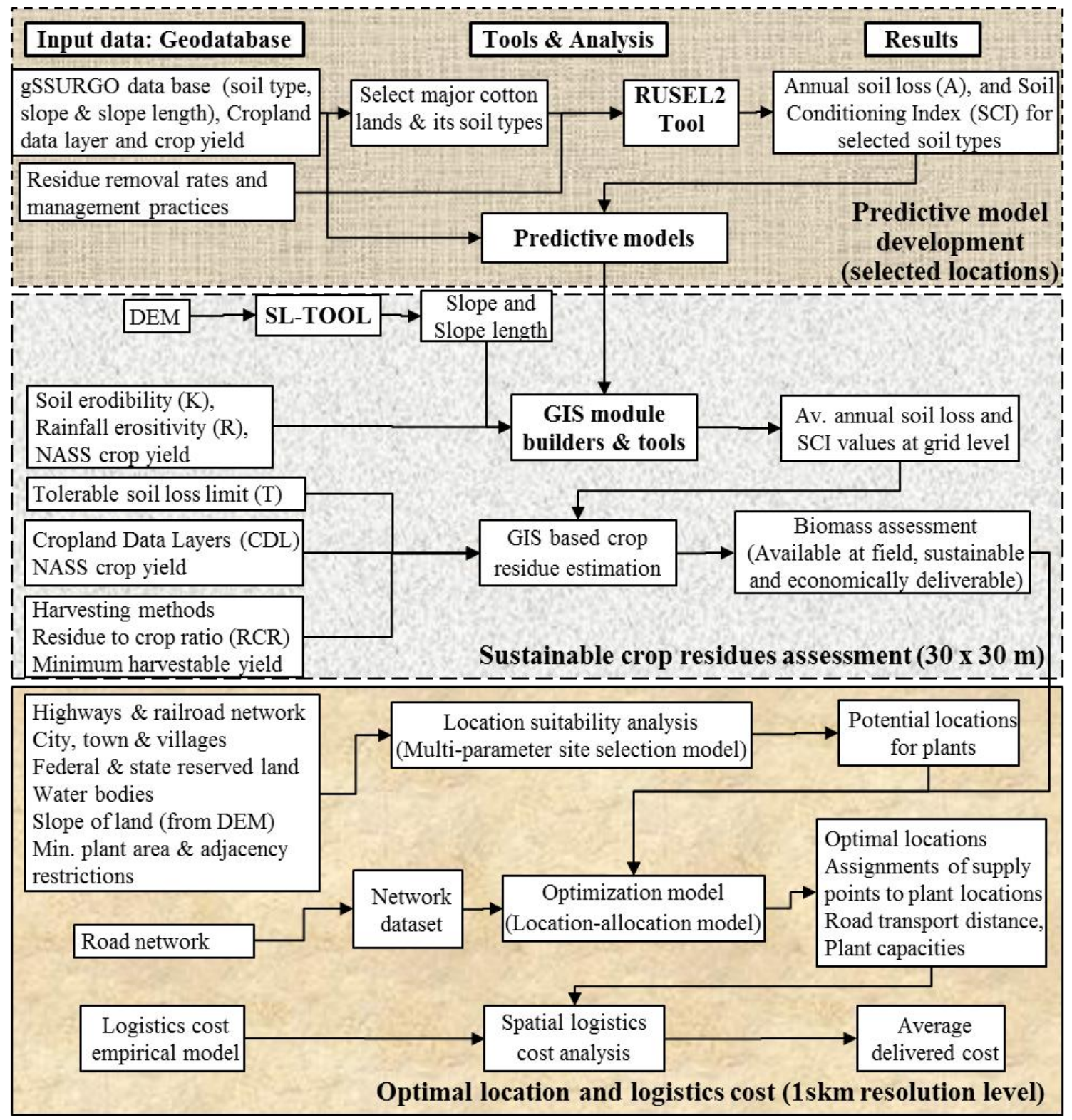

Figure 1: An integrated GIS-based biomass assessment methodology and conceptual modeling approach

Spatial information about soil properties, cultivated crops and crop yield, road network and other relevant inputs was collected in vector and raster format from various sources, including the geospatial data gateway from US Department of Agriculture (USDA) and US Geological Survey (USGS). All GIS data layers were projected to a local coordinate system. A spatial resolution of 30x30m was maintained for raster data layers during the biomass assessment analysis. RUSLE2 [36] software was used to estimate SE and SCI values at representative locations using location specific required inputs and crop 
management practice. Statistical software, JMP Pro 11 [37] was used for data analysis and development of predictive models. The ArcGIS 10.2 software [38], module builder and inbuilt tools (Spatial Analyst and Network Analyst) were used to build models and analyze the results [34].

\subsection{Predictive models to estimate SE and SCI values}

RUSLE2 tool was used to generate SE and SCI values with data from representative counties and major soil types for the study area [7]. Then, ANN prediction models were developed using RUSLE2 outputs (e.g., SE or SCI values) as the response to the location specific soil properties, topography, climate, crop yield and crop management and RRR input data (fig. 1). The soil parameters and crop data were collected from Gridded Soil Survey Geographic (gSSURGO) and National Agricultural Statistics Service (NASS) databases respectively. RUSLE2 was simulated for five levels of RRRs $0 \%, 30 \%, 60 \%$ $80 \%$ and $100 \%$ for certain management practices. Many ANN models were developed to select the best network configuration with the highest $\mathrm{r}^{2}$ and the lowest standard error value for estimating SE and SCI values. These ANN models were mimicked in the ArcGIS 10.2 to predict grid-level annual SE and SCI values using grid specific data.

\subsection{Sustainable assessment of crop residues}

The sustainable availability of crop residues at grid level were assessed with three primary sustainability criteria: (i) annual SE should be less than tolerable soil erosion limit (T); (ii) SCI should be more than zero; and (iii) the amount of harvested residues yield should be more than $2.5 \mathrm{dry} \mathrm{Mg} / \mathrm{ha}$. Crop residue availability at the farm level is highly influenced by the crop yield and its residue to crop ratio (RCR). The crop harvesting method could also impact the net amount of biomass to be left in the field. For example, cotton harvested with a lint-stripper removed $30 \%$ more residue with lint than that of a cotton picker harvester [39]. In general, crop residues (CR) availability at grid level (30x30m) were estimated using equation $1-\mathrm{a}, 1-\mathrm{b} \& 1$-c.

$\mathrm{ACR}_{k}{ }^{t}=\mathrm{A}_{k} * \mathrm{CY}_{k}{ }^{t} * \mathrm{CHM}_{k} * \mathrm{RCR} \quad \forall \mathrm{k} \& t$ 


$$
\begin{aligned}
& \mathrm{HCR}_{k}^{t}=\left\{\begin{array}{cc}
\mathrm{ACR}_{k}^{t} * \mathrm{HE}, & \forall \mathrm{ACR}_{k}^{t} * \mathrm{HE} \geq 2.5 \\
0, & \forall \mathrm{ACR}_{k}{ }^{t} * \mathrm{HE}<2.5
\end{array} \quad \forall \mathrm{k} \mathrm{\& t}\right. \\
& \mathrm{SHCR}_{k}{ }^{s}=\left\{\begin{array}{cc}
\mathrm{HCR}_{k}^{t}, & \mathrm{SE}_{k} \leq \mathrm{T}_{k} \text { and/or SCI } \\
0, & \mathrm{SE}_{k}>\mathrm{T}_{k} \text { and/or } \mathrm{SCI}_{k}<0
\end{array} \quad \forall \mathrm{k} \& t\right.
\end{aligned}
$$

Where $k$ and $t$ are unit farm land or grid (30x30m) and assessment year during a study period. $\mathrm{ACR}_{k}{ }^{t}$ and $\mathrm{HCR}_{k}{ }^{t}$ are available and harvestable crop residues respectively having crop yield $\mathrm{CY}_{k}{ }^{t}$ from $k^{\text {th }}$ unit land with area $\mathrm{A}_{k}$ during $t^{\text {th }}$ study period. The RCR, $\mathrm{HE}$ and $\mathrm{CHM}_{k}$ are residue to crop ratio, harvest efficiency and crop harvesting method factor respectively.

\subsection{Optimal plant location and logistics cost estimation}

\subsubsection{Identification of possible sites for bioenergy plant location}

The optimum location for a biorefinery can be influenced by the geophysical, environmental, social, and economic factors. Multi-criteria inclusion-exclusion spatial analyses were used to find suitable sites for establishing plants. The criteria and assumptions are described below:

- A plant should be located close to major state and national highways and rail networks to ensure connectivity and smooth traffic for large numbers of vehicles when transporting raw materials/products to/from the plant. It was assumed that a plant should be 1-3 km away from both road and rail networks.

- The distance between a plant and the nearest city(s), town(s) and village(s) should be optimized such that the plant is sufficiently far away from inhabited areas that plant operations do not interfere with human \& social activities, but sufficiently close in order to provide required resources to the plants. Therefore, a plant is assumed to be located between 5 and $10 \mathrm{~km}$ away from inhabited areas.

- The plant locations should avoid conservation lands, federal land, and reserve lands.

- The plant cannot be built on water bodies, wetlands, or rivers.

- The slope of the selected location should be less than $10 \%$ in order to reduce the cost of plant construction. 
- The individual area of selected site/location must be more than some limiting value, i.e., 10 ha in the case of a small size plant including storage space.

- Multi-criteria site-selection model may produce adjacent possible sites. Adjacent possible plant sites unnecessarily increase the size of location-allocation optimization model. Therefore, the minimum distance between adjacent selected plant sites was assumed to be $5 \mathrm{~km}$.

The inclusion analysis includes the intersection of two-sided buffer zones of major highways \& railways and one-sided buffer zones for urban areas which were created based on assumed buffer extents. In exclusion analysis, the conservation and wetlands and their outside buffers were excluded from the previously developed suitable buffer zone in exclusion analysis. The assumed factors were consistent with previous studies by Sultana \& Kumar [32], Zhang et.al. [40] and Mielenz [41]. Suitable land areas were converted to a raster data layer with a raster value of one. The slope was calculated using DEM for suitable land areas and a raster data layer was created using a reclassification tool based on a slope where the value was 1 if slope $<10 \%$ or 0 if slope $>=10 \%$. Then, all raster layers were multiplied and the pixels with raster value 1 were considered suitable land for plant location. The raster layer was converted to polygons and their areas were estimated. Polygons with an area greater than 10 ha were selected as possible plant locations and converted to points. The current analysis can produce a large number of adjacent plant locations which may not improve the logistics cost of the optimization problem, but may increase the size of it. A cluster heuristic approach (nearest neighbor algorithm) was used to filter very closely located adjacent possible plant sites.

\subsubsection{Optimal sites selection and biomass delivered cost estimation}

The mathematical formulation of a facility location model (linear programming) to select a certain number of plants with fixed capacities to minimize supply chain cost [42] was described below.

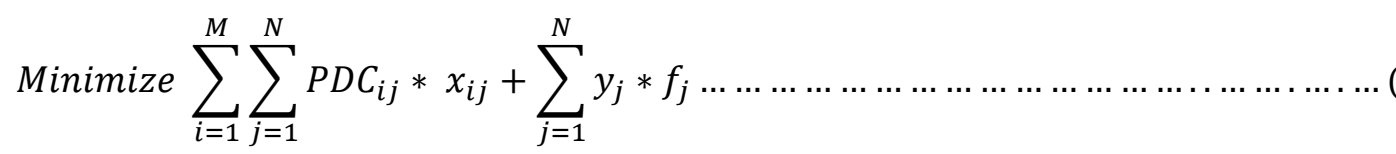


$P D C_{i j}=q_{i j}\left[F G_{i}+\left(c+a * d_{i j}\right)\right]$

Subject to

$\sum_{j=1}^{N} x_{i j}=1, \quad \forall i, i=1$ to $M$

$\sum_{i=1}^{M} x_{i j} * q_{i j} \leq y_{j} Q_{j}, \quad \forall j, j=1$ to $N$

$d_{i j} * x_{i j} \leq D, \quad \forall i \& j$

$\sum_{j=1}^{N} y_{j} \leq P$

Where, $P D C_{i j}$ is a plant delivered cost between supply ( $\mathrm{i}=1$ to $\left.\mathrm{N}\right)$ and demand $(\mathrm{j}=1$ to $\mathrm{M}$ ) locations. $x_{i j}$ and $y_{j}$ are binary decision variables (1/0, selected/not selected). The optimization model as formulated above selects "P" number of sites for plants of capacities $Q_{j}$ from "N" possible sites to optimize total supply chain cost for the studied region. The objective function in equation 2 minimizes the total cost of biomass delivered to the plants and their construction costs for a region/study area. The plant delivered cost (harvesting \& transportation cost) was calculated by using an empirical equation 3 where, $F G_{i}, d_{i j}, q_{i j}, c$ and a are farm gate cost of biomass, transportation distance (one-way) between supply points and plant location, quantity of biomass supplied to the plant, fixed transportation cost independent of travel distance and a constant respectively. It was assumed that a supply point should supply biomass to only one plant (equation 4). Equation 5 ensures that the quantity of supplied biomass should be less than the capacity of each plant and that supply point will only be assigned to a plant location selected in the optimum solution. The maximum transport distance was taken care of by equation 6 and the number of selected plant locations should be less than or equal to $\mathrm{P}$ as shown in equation 7 . 
The transportation cost of biomass is directly proportional to the transport distance and it can be assumed that the cost and capacity of the plants are the same at every possible location. So the objective function (equation 2) can be modified to minimize distance [32] as in equation 9.

Minimize $\sum_{i=1}^{N} \sum_{j=1}^{M} d_{i j} * q_{i j} * x_{i j}$

The heuristics based location-allocation model built in ArcGIS 10.2 tool was used to solve for optimal plant locations with reasonable time [34]. The location-allocation model requires at least three inputs as possible sites for plants, locations of supply points and transportation network dataset. The developed model was run for both capacitated and uncapacitated plants. The solution from the models provided the best-selected plant locations, the assignment of each supply point to an optimal location with respective transport distance and supply quantity to the plant location.

The total cost $\left(T C_{j}\right)$ of logistics and average feedstock delivered cost $\left(A P D C_{j}\right)$ at each selected plant location with a capacity $\left(Q_{j}\right)$ were calculated as equation 10 and 11 respectively.

$$
\begin{aligned}
& T C_{j}=\sum_{i=1}^{M}\left(F G_{i}+T_{i j}+S+P P_{j}\right) * q_{i j} \forall j, j=1 \text { to } P \\
& A P D C_{j}=\frac{T C_{j}}{Q_{j}}
\end{aligned}
$$

$F G_{i}$ and $T_{i j}$ were farmgate cost (includes harvesting, collection and stalking) and transportation cost for supplying biomass $\left(q_{i j}\right)$ from supply point ' $i$ ' to plant located at ' $j$ ' respectively.

\section{Case study \& input data}

The developed modeling approach was implemented to cotton lands from the state of Georgia for pellet production. The CS is one of the readily available crop residues in the southeast and the mid-south US, which is considered to be a negatively valued biomass as most of the farmers spend money and 
resources to remove standing CS from the field [43]. Cotton is one of the major crops cultivated in the southeastern US and the states of Texas and Georgia are the two leading cotton producing states with the largest amount of CS available for bioenergy application [30]. The estimation of biomass availability, SE, SCI, optimal plant location and logistics cost for the state of Georgia have analyzed at a spatial resolution of 30x30 m grids, and the duration of the study was from 2010 to 2014 .

\subsection{Assessment of CS availability, SE and SCI values}

The lint yield varies widely in the USA from 200 to $1200 \mathrm{~kg} \mathrm{ha}^{-1}$ [44]. The value of RCR was ranged from 2.77 to 5 and a median value of 4.0 was used in this study [45]. The experimentally estimated CS yield ranged from 2 to 7 dry $\mathrm{Mg} \mathrm{ha}^{-1}$ in the USA [43, 44]. The annual, county-level lint yield and cotton cultivation land raster data layers were obtained from National Agricultural Statistics Service (NASS) and CropScape of USDA respectively [46, 47]. Multiple simulations run on RUSEL2 software[48] were conducted for selected 11 counties with 48 types of soils (major soil types in selected counties) to estimate SE and SCI values using required inputs such as soil type, slope, slope length, crop yield, crop rotations and residue removal rate (RRR). The grid level input data and tolerable SE limit (T) were collected from the gSSURGO database. The spatial data related to rainfall erositivity (R-factor) and soil erodibility (K-factor) were obtained from PRISM Climate group and gSURGGO [49] database respectively. The selected counties belonged to major cotton-producing counties in the state of Georgia as well as dispersed geographically within the state. Only major soil types identified to represent more than $70 \%$ of total croplands in each county were chosen. For each soil type, the SE and SCI values were calculated using the RUSEL2 software tool considering five removal rates and three levels of crop yield (the lowest, an average and the highest during the study period).

The artificial neural network tool in JMP software [37] was used to configure the ANN models to predict responses (SE and SCI) using 12 geophysical and management practices and yield inputs. A number of different network structures of ANN models, transfer functions, learning rates, boosting and penalty options were tested to select the best neural network structure for predicting responses by 
comparing $\mathrm{r}^{2}$ and root mean square error values. An increase in the ANN model configuration complexity (no of nodes in hidden layers, high level of boosting) produced higher $\mathrm{r}^{2}$ values. However, an implementation of the ANN model transfer function with a geospatial tool (in ArcGIS) to perform calculations at a high resolution and large scale can create bottlenecks regarding processing time and data storage capacity. Therefore, ANN model having two hidden layers (6 nodes each in the 2nd layer and two nodes in the 1st layers) with TanH and Gaussian transfer functions were selected. The boosting option and a learning rate of 0.2 have been chosen to avoid model overfitting. A weighted decay penalty was considered to mitigate the over-fitting tendency of the ANNs. Two separate ANNs were configured, for predicting SE and SCI values. All data points were randomly split into three subsets: training (60\%), validation (20\%) and testing (20\%). These ANN models were mimicked in the ArcGIS 10.2 using module builder to predict grid level annual SE and SCI values with geospatial input data.

Slope and slope length are two most sensitive data that affect SE and SCI values and were estimated using slope length tool (SL-Tool) developed by Zhang et al. [40]. This tool use better slope length estimation algorithm (i.e., FCL - flow path and cumulative cell length) than currently used methods [50]. The effect of wind erosion on the southeastern states of the USA was assumed negligible [8, 51]. Previous studies estimate that the amount of residues required to be left in the field to prevent wind erosion was 0.07 to $0.62 \mathrm{Mg} / \mathrm{ha}$ considering conservational and conventional farm tillage practices respectively [8]. Therefore, the wind erosion estimation was not included in this study.

Three scenarios considered for the sustainable assessment of CS were:

Scenario1: CS yield > 2.5 dry $\mathrm{Mg} \mathrm{ha}^{-1}$;

Scenario 2: CS yield >2.5 $\mathrm{Mg} \mathrm{ha}^{-1} \&$ annual $\mathrm{SE}<\mathrm{T}$;

Scenario 3: CS yield $>2.5 \mathrm{Mg} \mathrm{ha}^{-1}$, annual $\mathrm{SE}<\mathrm{T} \& \mathrm{SCI}>0$.

Currently, a majority of cotton farmers in the state of Georgia practices conservation tillage (strip/no tillage) with some cover crops, i.e. rye [52]. The crop rotation for each grid was calculated using 
CropScape raster dataset and ArcGIS 10. 2 sequence tool. The data illustrated that majority of cotton land used for at least three years of continuous cotton cultivation in the past five years.

\subsection{Plant location optimization model and logistics cost estimation}

Vector datasets for transport network (rail \& highways); conservation lands; city, town \& village; water bodies and rivers were obtained from USGS and Georgia data clearinghouse [49, 53]. The road network datasets used in Network Analyst tools include highways, primary and secondary roads having attributes like permitted speed, road class, turn restrictions, etc. The Network Analyst tool used only turn restriction attributes of truck movement for finding the shortest road distance from a farm to plant location. The plant delivered cost and its supply curves for CS were developed using empirical equations and output from location-allocation model. Normally, the capacity of pellet plants is in the range of $0.04-$ 0.7 Tg in the USA. An increase in pellet plant capacity usually decreases the capital cost. However, the unit capital cost (\$/dry Mg) remain unchanged for a plant capacity of more than 200,000 dry $\mathrm{Mg}$ onwards) [54]. In this study, the location optimization model was run with two conditions (i) fixed annual plant capacity $(200,000$ dry Mg); (ii) Uncapacitated plants with a maximum transport distance limit of $100 \mathrm{~km}$, one-way.

Sahoo and Mani [30] studied various CS harvesting and logistics options and found that the large rectangular bales option was the least expensive format to deliver CS to a bioenergy plant. The detailed logistics cost estimation procedure was described in Sahoo and Mani [30] and the best-fitted regression equations to estimate farm gate $\left(F G_{i}\right)$ and transportation $\left(T_{i j}\right)$ costs on biomass yield $\left(Y_{i}\right)$ and transport distance $\left(d_{i j}\right)$ respectively are presented in equations 12 and 13.

$$
\begin{aligned}
& F G_{i}=107.94 * Y_{i}^{-0.91} \\
& T_{i j}=9.65+0.123 * d_{i j}
\end{aligned}
$$


The additional costs for storage $(S$, tarped storage, $8 \$ / \mathrm{dry} \mathrm{Mg})$ and preprocessing $\left(P P_{j}\right.$, tub-grinding, 10 \$/dry $\mathrm{Mg}$ ) were also included to the feedstock delivered cost.

\section{Results}

\subsection{GIS-based sustainable assessment of CS}

Cotton is the $4^{\text {th }}$ largest field crop in the U.S. (mostly in southern states) regarding cultivated area as well as the net return to farmers [46]. In the study, cotton land from the State of Georgia was selected and it covers about 1530 different soil types. However, ten major types of soil spread over $44 \%$ of the total cultivated cotton land. The estimated sustainability indicators (SE and SCI) values using RUSLE2 tool were presented in figure 2 for major soil types from eleven selected counties.
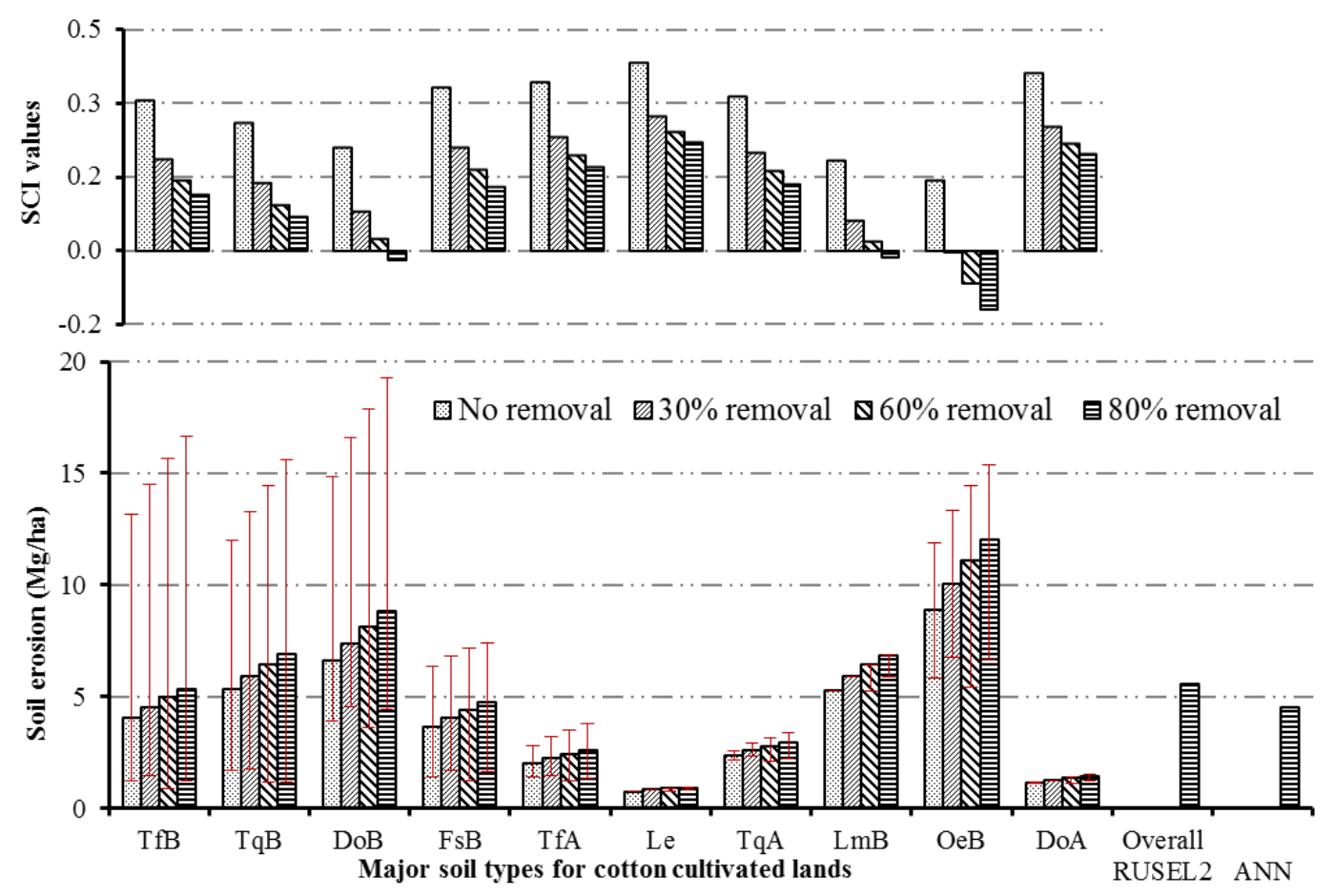

TfB , TqB , TqA \& TfA - Tifton Loamy sand $100 \%$, FsB - Fuquay Loamy sand, DoB \& DoA- Dothan loamy sand, FsB - Fuquay loamy sand, Le - Leefield loamy sand 95\%, LmB - Lucy loamy sand 100\%, OeB Orangeburg loamy sand $80 \%$. RUSLE2 tool was simulated to produce SE and SCI values.

Figure 2: Variations in annual SE and SCI values with respect to residue removal rate for major soil types in cotton cultivated lands in the State of Georgia, USA 
The annual average SE was estimated to about $5.5 \mathrm{Mg} /$ ha for selected cotton cultivated lands and was comparable with the study by Endale et al. [52]. Soil erosion variations were mainly due to the difference in slope, slope length, crop yield and climate which may vary within the farm lands or between two adjacent grids (30x30m). Therefore, grid specific SE and SCI values were required to estimate sustainable assessment of crop residues. The RUSLE2 tool was simulated to accommodate a wide range of locations specific inputs such as soil properties, crop management practices, crop yield, slope, slope length and rainfall for eleven counties and forty-eight major soil types dispersed across the state of Georgia. The predictability for SE $\left(r^{2}=0.99\right)$ and SCI values $\left(r^{2}=0.98\right)$ with ANN model were robust and the results were on par with RUSLE2 simulation data. The $\mathrm{r}^{2}$ values for these models were high and consistent during training, validation, and testing phases as illustrated in table 1.

Table 1: Performances of the developed ANN models

\begin{tabular}{lccccc}
\hline & Parameter & & Training & Validation & Testing \\
\hline \multirow{2}{*}{ Model 1 } & \multirow{2}{*}{ SE } & $\mathrm{r}^{2}$ & 0.99 & 0.99 & 0.98 \\
& & RMSE & 0.0 .40 & 0.41 & 0.44 \\
\hline \multirow{2}{*}{ Model 2 } & \multirow{2}{*}{ SCI } & $\mathrm{r}^{2}$ & 0.98 & 0.98 & 0.98 \\
& & RMSE & 0.02 & 0.02 & 0.02 \\
\hline
\end{tabular}

ANN models predicted that about $1.65 \%, 2.44 \%, 3.56 \%$ and $4.55 \%$ of the total cotton cultivated land were subjected to high SE (annual SE > T) considering 0\%, 30\%, 60\% and $80 \%$ of CS removal from the field respectively. But only $3.7 \%$ of the total cotton cultivated land had the negative SCI values at $80 \%$ residue removal rates. The total cotton residues in the field, possible harvestable amount (scenarios $1 \& 2$ ) and sustainably harvestable amount (scenario 3) from 2010 to 2014 are presented in table 2. The variations among the availability of CS from all three scenarios were negligible since we assumed the best crop management practices (conservation tillage practices with cover crop) in this study. The amount of residue required to preventing excessive SE and maintaining positive SCI values primarily provided by cover crop used in the cotton land. Therefore, $80 \%$ of CS can be removed from the majority of the cotton land keeping the sustainability indicators within the critical limit. However, conventional tillage without cover-crop management practice assumption in the model may substantially increase the soil erosion and 
reduce the SCI values and ultimately reduce the availability of sustainable CS from the study area. From an environmental point of view, scenario 3 can be an ideal approach to assessing sustainable crop residues for bioenergy applications.

Table 2: Annual CS availability in the state of Georgia, the USA from 2010 to 2014

\begin{tabular}{|c|c|c|c|c|c|c|c|c|c|}
\hline \multirow[b]{2}{*}{ Year } & \multirow{2}{*}{$\begin{array}{c}\text { Av. stalk } \\
\text { yield (dry } \\
\mathrm{Mg} / \mathrm{ha})\end{array}$} & \multicolumn{2}{|c|}{$\begin{array}{c}\text { Total availability of } \\
\text { CS in the field }\end{array}$} & \multicolumn{6}{|c|}{ Sustainable availability of CS } \\
\hline & & $\begin{array}{c}\text { Area } \\
(000, \\
\text { ha) }\end{array}$ & $\begin{array}{l}\text { Stalk }(000, \\
\text { dry } \mathrm{Mg})\end{array}$ & $\begin{array}{c}\text { Sc } \\
\text { Area } \\
(000 \text {, } \\
\text { ha) }\end{array}$ & $\begin{array}{l}\text { nario } 1 \\
\text { Stalk }(000, \\
\text { dry } \mathrm{Mg})\end{array}$ & $\begin{array}{c}\mathrm{Sc} \\
\text { Area } \\
(000, \\
\text { ha) }\end{array}$ & $\begin{array}{l}\text { enario } 2 \\
\text { Stalk }(000, \\
\text { dry } \mathrm{Mg})\end{array}$ & $\begin{array}{c}\text { Sc } \\
\text { Area } \\
(000, \\
\text { ha }) \\
\end{array}$ & $\begin{array}{l}\text { enario } 3 \\
\text { Stalk }(000, \\
\text { dry } \mathrm{Mg})\end{array}$ \\
\hline 2010 & 3.7 & 559 & 2,067 & 520 & 1,559 & 524 & 1,568 & 515 & 1,543 \\
\hline 2011 & 3.5 & 697 & 2,459 & 572 & 1,690 & 576 & 1,701 & 566 & 1,672 \\
\hline 2012 & 4.9 & 502 & 2,449 & 480 & 1,875 & 484 & 1,889 & 475 & 1,856 \\
\hline 2013 & 3.7 & 548 & 2,024 & 492 & 1,485 & 496 & 1,496 & 487 & 1,470 \\
\hline 2014 & 4.0 & 535 & 2,140 & 500 & 1,613 & 504 & 1,626 & 495 & 1,598 \\
\hline $\begin{array}{c}\text { Average } \\
(2010- \\
2014)\end{array}$ & 4.0 & 568 & 2,228 & 513 & 1,644 & 517 & 1,656 & 508 & 1,628 \\
\hline
\end{tabular}

Assessment based on considering few scenarios as (1) stalk yield $>2.5$ dry $\mathrm{Mg}$, (2) amount of stalk yield $>2.5$ dry $\mathrm{Mg}$ and $\mathrm{SE}<\mathrm{T}$ and (3) stalk yield $>2.5$ dry $\mathrm{Mg}, \mathrm{SE}<\mathrm{T}$ and $\mathrm{SCI}>0$

The sustainable availability of CS in the state of Georgia was estimated to about $68-76 \%$ of total residues available in the field. Figure 3 shows the top ten counties that contributed about $38 \%$ of sustainably available CS. According to Perlack [1] in the Billion Ton study, the annual availability of CS in Georgia was about 0.38 million dry $\mathrm{Mg}$ which was about $25 \%$ of the current assessment (1.63 million dry $\mathrm{Mg}$ ). Shumaker et al. [55] estimated about 2.4 million Mg of CS from Georgia assuming the higher residue yield of $5 \mathrm{Mg} / \mathrm{ha}$. The temporal variations in annual CS availability in this study were ranged from $-14 \%$ and $10 \%$ of average value due to yearly yield variations and spatial shifts in cotton cultivation farm locations. These variations were significantly larger at the county level (from $-100 \%$ to $41 \%$ in ten counties as presented in figure 3) as well as at the farm level (data not shown here). 


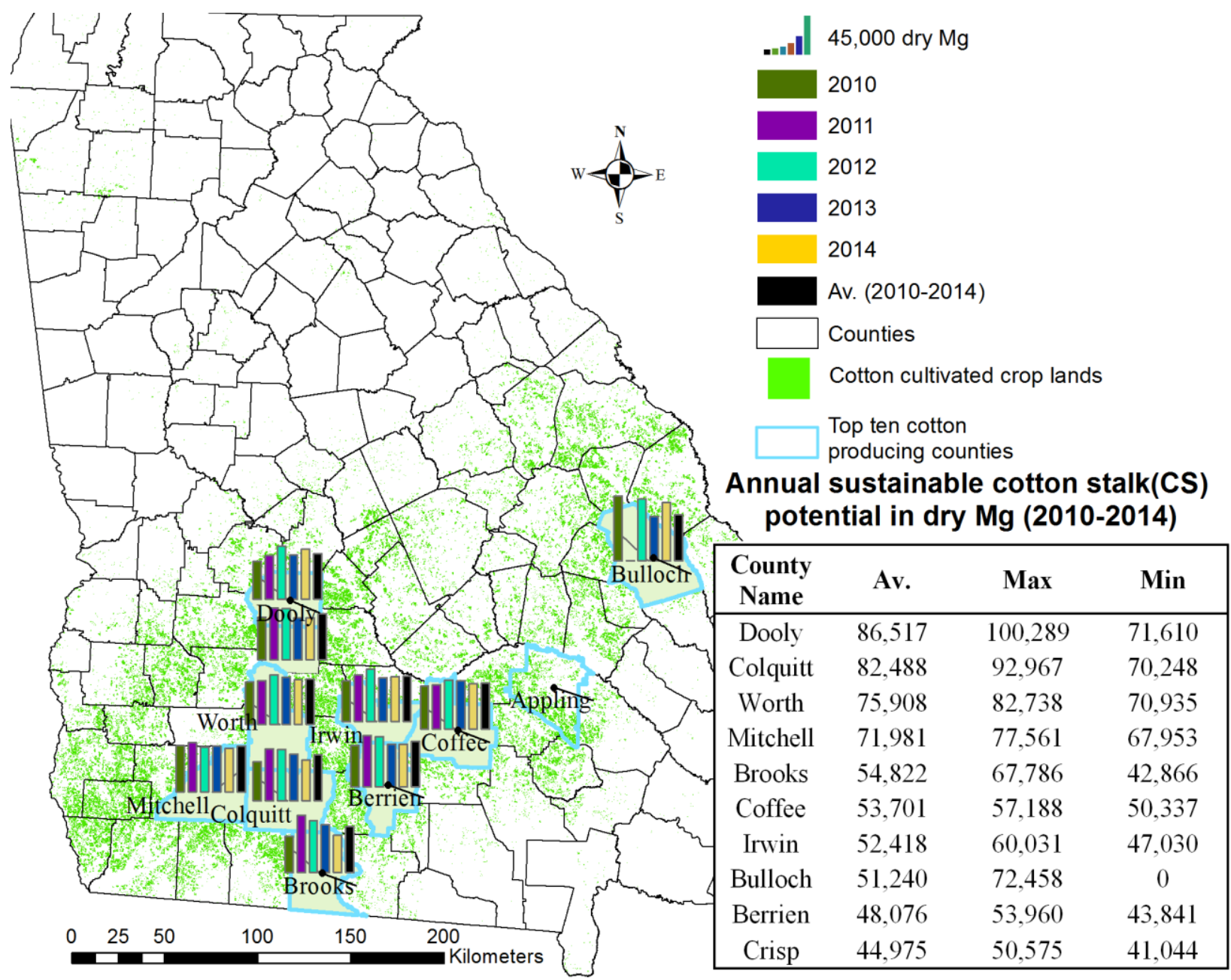

Figure 3: Sustainable CS availability from top ten counties in the state of Georgia, the USA from 2010 to 2014

The farm/grid level sustainable crop residue assessment has multiple uses for operational and strategic decision-making activities in the biomass supply chain. The detailed high-resolution biomass availability can be used for estimating farmer's compensation based on residue removal at the farm scale, planning field logistics activity [56], routing of trucks for biomass transport and estimating farm level logistics cost and greenhouse gas emissions. Usually, county level biomass availability (assumed to be present at the centroid of a county) was used in optimization models for designing optimal biomass supply chain in literature which may not be actual representations of the supply points. The grid level biomass availability can be used to find the center of mass of available biomass in counties for the above 
use or provide farm level supply locations for higher resolution studies as presented in the remaining sections.

\subsection{Optimal location for pellet plants}

\subsubsection{Identification of suitable sites for plant location}

GIS-based multi-criteria inclusion-exclusion analysis method was used to identify a comprehensible number of potential sites for locating a pellet plant. Initially, about 329 potential locations were identified, but most of them were found in clusters that were very close to each other. It was observed that these clusters of many locations unnecessarily increased the size of optimization problem without much influence on the optimal locations and logistics cost. Therefore, a cluster heuristics was used to reduce a small number of potential sites. However, the best location in a cluster can be identified assuming additional selection criteria such as the cost of land, tax incentives, available service, and competitors. The temporal and spatial variations in residue yield could influence the optimal plant location as well as the delivered cost of feedstock. The optimization model and logistics cost analysis were only for sustainable availability of CS (from scenario 3) in the state of Georgia. The sustainable availability of CS from scenario 3 was used for identifying optimal plant location and estimating biomass logistics cost.

CS available from cotton land in one square kilometer area was considered as a supply point/single source of biomass. The number of supply point varied annually between 40,000 and 46,000. The sustainable availability of CS from each supply point was ranged between 0.4 and 387.3 dry $\mathrm{Mg} / \mathrm{y}$. About $40 \%$ of the supply points had less than 10 dry Mg of CS, which contributed only $4 \%$ of total available CS from the studied region. These supply points could increase the size of the optimization problem which was neglected without compromising on the results. The sustainably available CS in the study region could support about 7-9 pellet plants with an annual plant capacity of 200,000 dry Mg. 


\subsubsection{Optimal plant location and its supply curves}

The location-allocation model developed with Network analyst tool identified the optimal sites by minimizing weighted distance (tonne-km) from supply points to the selected plant sites. The model was simulated using both five-year average as well as yearly biomass availability (2010, 2011, 2012, 2013 and 2014) data to evaluate the effects of temporal and spatial variability on the supply potential from each biomass supply grids (one sq.km).

\subsubsection{Optimal plant locations (capacitated)}

Figure 4 shows the seven optimal plant sites and biomass draw area with biomass accumulation capacity, logistics cost, and average transport distance. A GIS-based multi-criteria decision model was used to minimize a large number of possible sites to 93 assuming adjacency constraints for the study area. The location-allocation model identified seven capacitated (200,000 dry Mg annual capacity) optimal sites in the study area. These optimal locations were generated using five-year average CS availability (2010-2014) data from each grid. For cotton stalk, a small-scale biorefinery with an average plant capacity of 200,000 dry Mg can be useful in establishing successful bioenergy sector in the US than a large scale cellulosic biorefinery (>800,000 dry Mg) envisioned by the Department of Energy (DOE). The delivered plant gate cost of CS to the optimal sites ranged from 68 to $75 \$ / \mathrm{dry} \mathrm{Mg}$. The plant gate cost did not include any cotton farmers' compensation to replenish nutrient removal due to the removal of CS. However, they spend about 10 to $15 \$$ dry Mg for mulching CS into the soil which is not required if CS is removed from the field (cost saving for cotton farmers). The difference in delivered cost among seven optimally located plants was mainly due to the difference in farmgate cost influenced by the CS yield data. The increase in the average transport distance did not affect the total delivered cost and the result was contrary to previous study by Sultana and Kumar [54]. Among seven optimal plant sites, the site 5 is the most sustainable plant as it would receive the least cost CS supplied from cotton lands with lower SE and positive SCI value. 


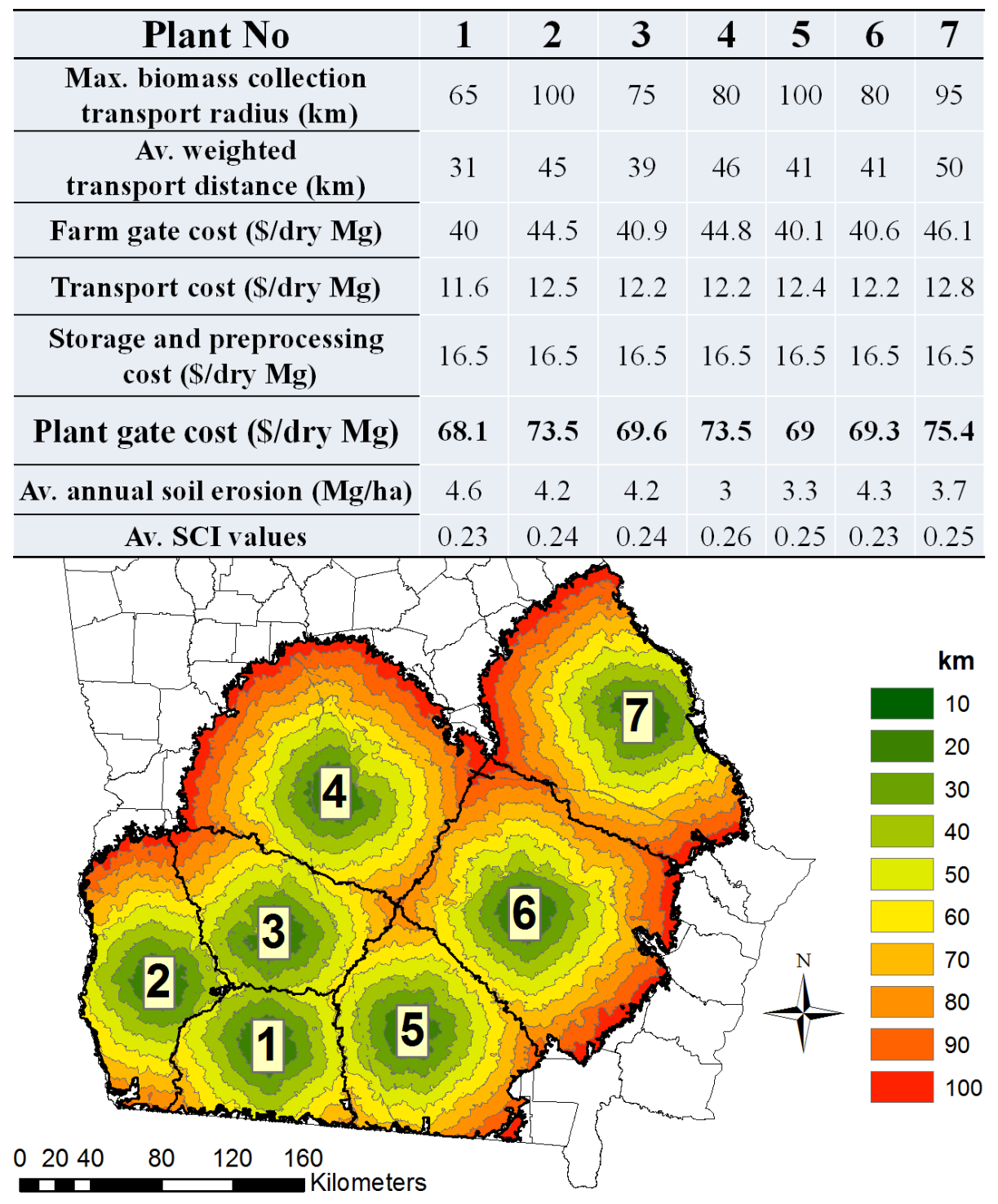

Figure 4: Optimal plant locations (7 plants with 200,000 dry Mg capacity) and its location characteristics

For example, the average biomass transport distance for plant site $1 \& 5$ was 31 and $41 \mathrm{~km}$ respectively, but both plant sites had similar delivered cost. However, the increase in farmgate cost increased the plant gate cost. The previous study by Sokhansanj et al. [36] reported that $1 / 3^{\text {rd }}$ increase in yield decreased the farm gate cost by $1 / 5^{\text {th }}$ for crop residues during harvesting. If the farm gate cost dominates the transport cost, a higher capacity pellet plant can be built to procure low-cost biomass available far from the plant site [54]. Therefore, an uncapacitated location-allocation approach could identify plant location with unique supply curve characteristics. 


\subsubsection{Optimal plant locations (Uncapacitated)}

The optimal plant locations and its biomass supply potentials were presented in figure 5 using yearly (a to e) and five-year average residue available data (f). The capacity of the plants ranged from 70,000 to 400,000 dry Mg with an average cumulative plant delivered cost of CS ranged from 69 to 75 \$ $/ \mathrm{dry} \mathrm{Mg.}$ The figure 5 further illustrated that an increase in plant capacity did not always increase the plant gate cost, which is often assumed for deciding the optimal plant capacity by previous studies [32, 54]. For example, plant location 1 and 5 had the similar average plant gate cost (69 \$/dry Mg), but the former (site 1) could accumulate $250 \%$ more CS as compared with that of a later (site 5) (figure 5f). The highest capacity plant (site 1) had the lowest plant gate cost due to the high concentration of CS availability within the plant radius. In this study, the CS yield variations and transport distances were dominant factors influencing the optimal plant location. The temporal variations in CS availability and residue yield also influenced the optimal plant location, average transport distance and delivered cost. However, the

optimal site for the large capacity plant (>200,000 dry Mg/y) did not change due to a large number of close supply points (Figure 5). 


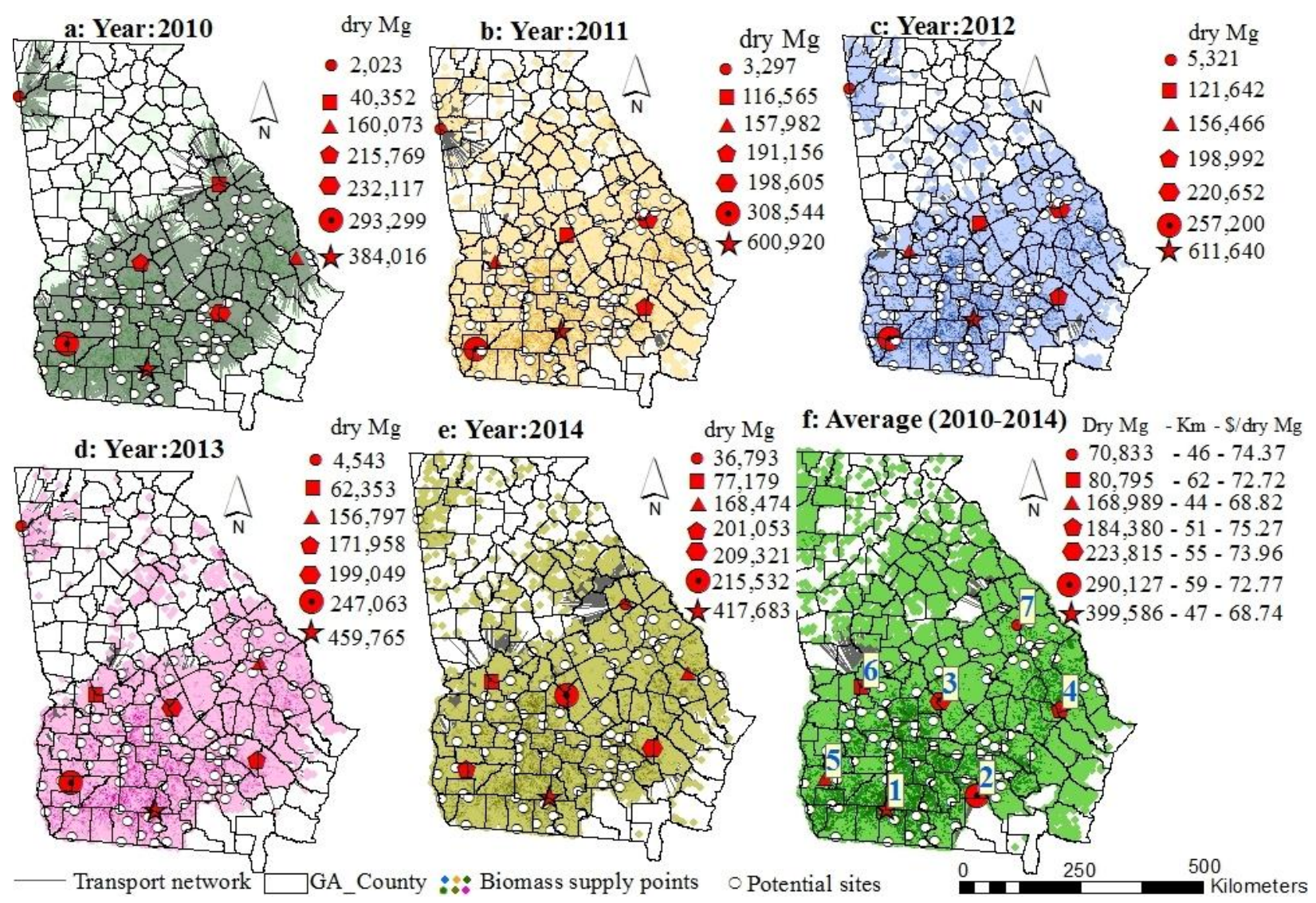

Figure 5: Optimal plant locations (7 nos, uncapacitated) and respective annual possible CS accumulation from 2010 to 2014.

The temporal and spatial variations in crop residues yield and a spatial shift in the actual cultivation of specific cotton lands between years could highly influence the optimal plant location and its plant capacity (Figure 5). The yearly variations in plant capacities were mainly due to CS yield variations rather than a spatial shift in cotton land locations, especially for higher capacity plant locations. The optimal locations for the largest capacity plant site shifted every year, but the shifts were marginal, e.g. less than $30 \mathrm{~km}$. The annual shifts in plant locations and its capacities could affect the average delivered cost of biomass to the plant. Therefore, the location-allocation model for identifying optimal plant locations should consider both the temporal and spatial variations of sustainably available biomass to minimize risks associated with the consistent annual availability of biomass and its variations in delivered cost. Real-time assessment of sustainably available feedstock for any given year could further reduce feedstock availability risks for a biorefinery. In addition, bioenergy investors and stakeholders should consider other 
factors (e.g., change in non-food crop policies and, lint and energy market demands) affecting the bioenergy plant locations and feedstock security.

The effect of plant capacity on the biomass supply curves and plant gate cost was shown in Figure 6. The solid horizontal lines represent the change in average plant gate, farm gate and transport costs with an increase in plant transport distance (radius). The vertical columns show the biomass availability from the bands of $5 \mathrm{~km}$ road distance $(0-5 \mathrm{~km}, 5-10 \mathrm{~km}, \ldots, 95-100 \mathrm{~km}$ actual road network distances) around the plants. It can be inferred that the plant site 1 was located in a region with higher CS yield or higher percentage of cropland dedicated to cotton than that of plant site 3.

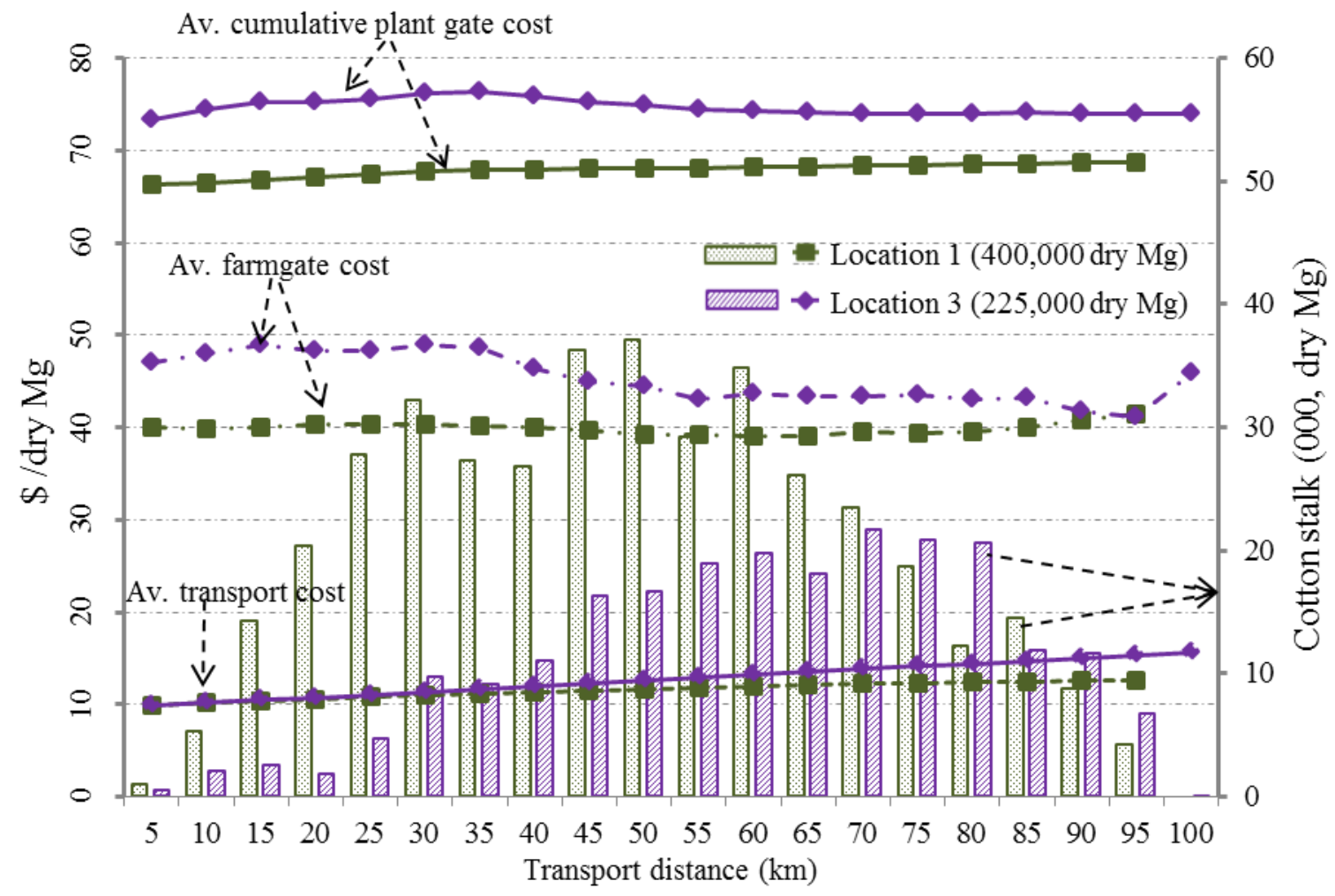

Figure 6: Average farm gate, transportation and cumulative plant gate cost of the CS for plant location 1 and 3 and CS (accumulated from $5 \mathrm{~km}$ width strips around the plant) potential with transport distance from each plant location

The plant at site 1 could accumulate a large amount of CS ( 2X times) as compared with site 3 from similar transport distances. The transport cost of CS was marginally increased with increase in transport 
distance. However, it did not influence the overall plant gate cost due to the large variation in farmgate cost determined by CS yield. Figure 6 further illustrated that the plant at site 2 could draw a lot of crop residues from farther distances $(>60 \mathrm{~km})$ due to lower farm gate cost and higher CS yield potential. Therefore, the biomass draw distance did not always contribute to higher plant gate cost as often assumed in the previous studies [32].

\subsection{Sustainability and supply risks}

The sustainable removal rate of (dry $\mathrm{Mg} \mathrm{ha}^{-1}$ ) of crop residues for bioenergy application is often estimated considering the impacts of biodiversity, land use change/pattern, soil erosion, soil health, soil and watershed protection and invasive species. Among various sustainability indicators, soil erosion and soil health are the two primary indicators measured by SE and SCI values respectively to protecting the long-term health of the soil/watershed. For cotton stalks, the soil health and water quality can be managed by keeping the indicator values within the critical limits, while removing the residues for bioenergy applications [7]. From an economic perspective, the cotton land having a minimum stalk yield of 2.5 dry $\mathrm{Mg} \mathrm{ha}^{-1}$ was accounted for the sustainable assessment of CS. From an environmental sustainability perspective, the impacts of biodiversity, indirect land use change, the inclusion of invasive species, etc. are important to assess biomass sustainability. For the case study, the ecological impacts of removing cotton stalk could be positive as the removal of cotton stalk or mulching into the soil prevents pest infestation, (e.g., pink cotton bollworm). The conventional approach to mulching CS in the field causes inconvenience during planting season in the subsequent year. Also, the mulching operation accelerates the soil erosion due to high soil disturbance, and it creates a significant economic burden to cotton farmers in the US [57]. However, the ecological benefits of removing cotton stalk for bioenergy application still needs to be quantified. The direct and indirect land use change impacts for CS could be minimal, as it is an underutilized by-product from cotton land and does not compete with food and feed, rather provides additional incentives to farmers. The impact of invasive species on the cotton lands is little known due to the removal of CS and requires further research. Therefore, the sustainable removal rate of CS could be 
managed and controlled by the SE and SCI values. However, further research is necessary to investigate the effect of removing cotton stalk on the long-term soil health.

Bioenergy supply chain inherently possesses some risks related to uncertainties in feedstock supply and its delivered cost, market demand, bioenergy policy, labor market and financial instability as similar to any other commodity supply chain. From the feedstock supply perspective, we have addressed the supply risks and its delivered cost to a biorefinery at the field/grid level. Also, biomass supply is highly exposed and sensitive to inclement weather and severe drought conditions. However, most of the cotton fields in the southern states are less susceptible to extreme weather events except hurricanes and sometimes drought. The sustainable availability of CS estimated in this study varied from 1.5 and 1.8 million dry $\mathrm{Mg}^{-1}$ for the past five years (2010-2014) including a severe drought year of 2012 (Table 2). Although the total area of cotton land had reduced to 475 ha, the sustainable availability of CS did not affect due to the relative increase in overall cotton yield in 2012. However, climate risk could pose a challenge to a biorefinery to secure feedstock supply, and they could be minimized and managed by adapting effective storage strategies, diversify feedstock types and downsizing the biorefinery operations or increasing the biomass draw radius.

\section{Discussions}

The spatial and temporal variations in soil properties, topography (mainly, percent slope and slope length), crop yield, climate and crop management practices can be natural to any geographic location. The complex interactions among these parameters decide the sustainable availability of crop residues for bioenergy application. The ANN predictive models captured the high-resolution field data to estimate sustainability indicators for assessing the sustainable availability of biomass reliably without compromising the long-term soil heath and computing time necessary for a large study area.| Most of the previous sustainable biomass assessment studies conducted at the soil polygon level used the average slope and slope length for the entire soil polygon area (ranges from 1 to 100,000 ha) to estimate 
sustainability indicators [7, 16-17]. Since the slope and slope length vary significantly within the soil polygon area, the estimation of SE and SCI values could be inaccurate. Whereas in the grid level (30x30m) assessment, the slope and slope length for each grid are accurately calculated using the SL-tool to estimate SE and SCI values to assess the sustainable availability of biomass. Figure 7 demonstrates the differences in the SE and SCI values and biomass availability using the grid-level and the soil polygon level assessments. For example, The soil polygon level assessment for a sample area located in Dooly County in the State of Georgia estimated a high soil erosion rate (10-15 Mg/ha) and a negative SCI value indicating no CS should be removed (Figures 7c \& 7d). The grid-level assessment of the same area estimated a low soil erosion rate $(5-10 \mathrm{Mg} / \mathrm{ha})$ and a positive $\mathrm{SCI}$ value indicating the CS could be removed or available for bioenergy application (Figures 7a \& 7b). Also, the soil polygon level analysis underestimated the sustainable availability of CS by about $28 \%$ due to inaccurate topography data compared with that of grid-level analysis. The accuracy of grid-level assessment data could be further improved using biomass yield monitoring or the remote sensing methods [17]. The grid-level assessment model can be used to develop biomass supply curves precisely, to schedule biomass supply to a biorefinery and to monitor field-specific soil health on a regular basis. Also, it can be used to identify optimal biorefinery site and to estimate actual biomass delivered cost and draw area for managing and controlling supply risks and developing suitable risk mitigation measures. 


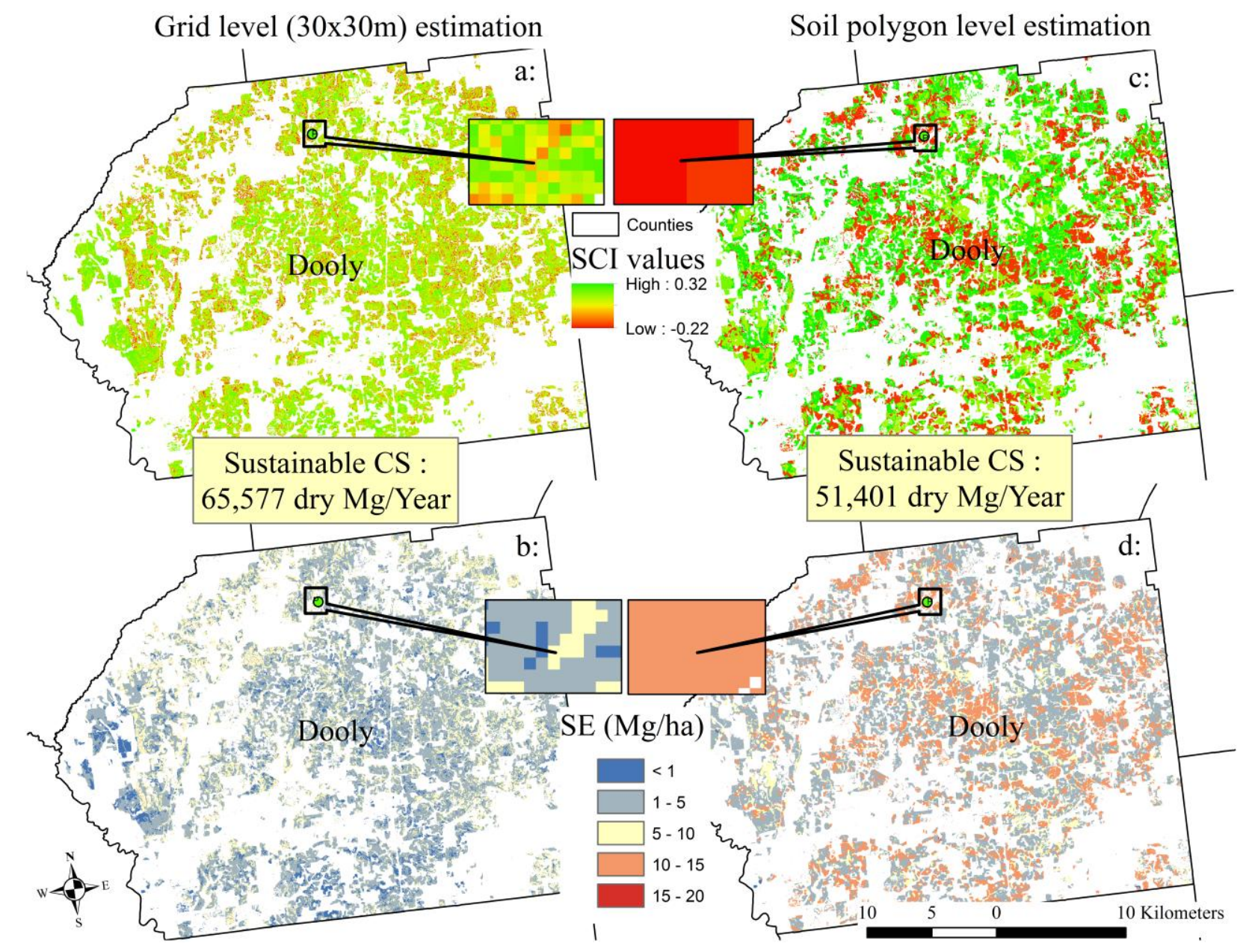

Figure 7: The differences in spatial distribution of SCI and SE values and sustainable availability of CS using grid level (30x30m) and soil polygon level assessments.

The accurate and reliable availability of biomass at the grid level is critical for identifying the optimal biorefinery site with feedstock delivered cost. The grid-level assessment model generates a number of biomass supply points within the study area as opposed to a county-centered supply points to identify the optimal site and draw radius for a biorefinery. Figure 8 demonstrates the differences in identifying optimal site and average CS transport radius estimated using the county-centered and one sq.km gridcentered supply points on the optimal location and transport radius for a biorefinery. For example, the optimal site for plant 1 identified with county-centered supply point (see Figure 8a) was shifted towards the southwest and underestimated the average transport radius $(32.4 \mathrm{~km})$ compared with that of one 
sq.km-centered supply point analysis (Figure 8b). However, the optimal site for plant 2 did not affect the biorefinery, but the county-centered supply point analysis overestimated the average transport radius to $46.6 \mathrm{~km}$. Therefore, grid-centered supply points can be useful in identifying optimal biorefinery site, and they can be used to develop feedstock supply curves and manage supply risks for a biorefinery.

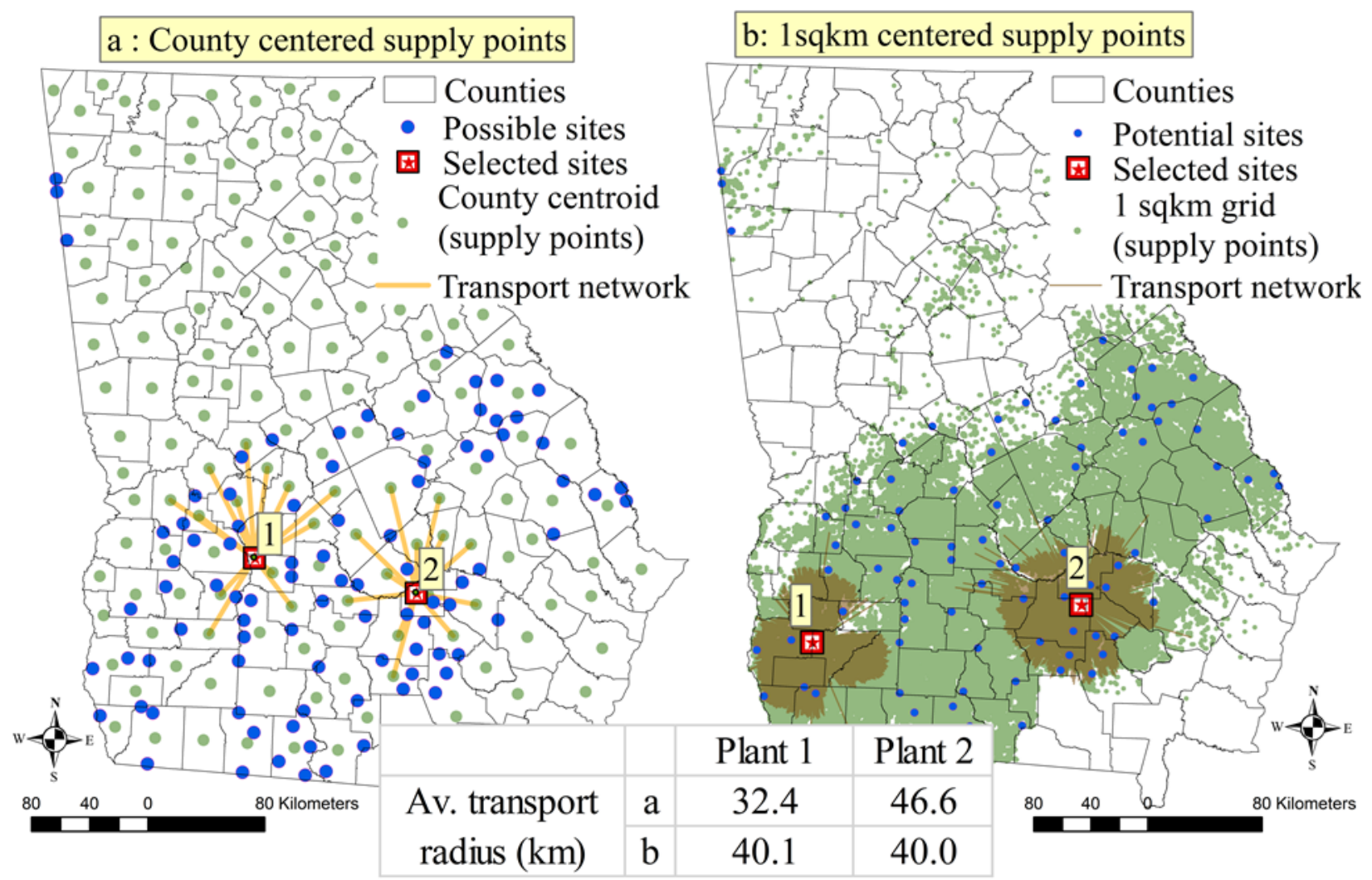

Figure 8: Identification of an optimal site (annual capacity 200,000 dry Mg) using (a) county-centered and (b) $1 \mathrm{sqkm}$ grid-centered supply points.

\section{Conclusions}

An integrated GIS-based sustainable biomass assessment and supply logistics model was developed at high spatial resolution ( $30 \times 30 \mathrm{~m}$ grid size) to identify optimal biorefinery site and demonstrated with a sustainable assessment of cotton stalk (CS) for the State of Georgia. The sustainable availability of CS was estimated based on the economic feasibility and long-term soil health measured by annual Soil Erosion (SE) and Soil Conditioning Index (SCI) values. The sustainability parameters at the grid level 
were estimated using Artificial Neural Network (ANN) prediction models developed with high accuracy for CS. The developed model estimated that about 1.6 million Mg of CS is sustainably available to build seven pellet plants with an annual plant capacity of 200,000 dry Mg in the State of Georgia, USA. The plant gate delivered cost of CS ranged from 68 to 75 \$dry Mg without farmers' incentives. The spatial variations in the topography and yield data at the grid level had directly affected the sustainable assessment of CS and the optimal plant location. The developed model can be used to schedule feedstock delivery and manage supply risks and maintain long-term soil health. It can also be extended to assess the sustainable availability of multi-feedstocks for other regions in the US to reduce uncertainties and risks associated with spatial and temporal variations.

\section{Acknowledgement}

This project was partly supported by the USDA - NIFA Biomass Research and Development Initiative (BRDI) grant (Grant \# 2012-1008-2032). 


\section{Nomenclature}

\section{General}

ACR Available crop residues

ANN Artificial neural network

CHM Crop harvesting method

$\begin{array}{ll}\text { CR } & \text { Crop residues } \\ \text { CS } & \text { Cotton stalk } \\ \text { CY } & \text { Crop yield } \\ \text { DEM } & \text { Digital elevation model }\end{array}$

GHG Greenhouse gas emissions

GIS Geographic information system

HCR Harvestable crop residues

HE Harvest efficiency

Mg Mega gram

RCR Residues to crop ratio

RRR Residue removal rates

RUSLE2 Revised universal soil loss equation 2

SCI Soil conditioning index

SE Soil erosion

SHCR Sustainably harvestable crop residues

\section{SL-Tool Slope-Length tool}

$\mathrm{T} \quad$ Tolerable soil loss limit

TC
Total cost

\section{Index}

$k \quad$ Unit area of cropland/grid (30 x $30 \mathrm{~m})$

$t$ Assessment year

\section{Resource assessment}

$\mathrm{A}_{k} \quad$ area of unit cropland or grid (ha)

$\mathrm{ACR}_{k}{ }^{t} \quad$ available crop residue in a grid $i($ dry $\mathrm{Mg})$ in a year $t$

$\mathrm{CY}_{k}{ }^{t} \quad$ crop yield $\left(\mathrm{Mg} \mathrm{ha}^{-1}\right)$ in grid $k$ in a year $t$

$\mathrm{CHM}_{k}$ crop harvesting method factor (example, 1.0 for cotton picker) for a unit land $k$

$\mathrm{HCR}_{k}{ }^{t} \quad$ harvestable crop residues (dry $\mathrm{Mg}$ ) in a grid $k$ in a year $t$

Index

$i \quad$ Represents supply sources of feedstocks, $i$ $=1,2, \ldots \mathrm{M}$

$j \quad$ Represents the possible plant sites, $j=1,2, . . \mathrm{N}$

Facility location model formulation and logistics cost estimation

$x_{i j} \quad$ Binary decision variable, $1 / 0=$ feedstock is supplied/not supplied from source $i$ to plant site at $\mathrm{j}$

$y_{j} \quad$ Binary decision variable, $1 / 0=$ plant is located/not located at site $j$

$f_{j} \quad$ Capital cost of plant at site $\mathrm{j}$

$q_{i j} \quad$ Quantity of feedstock supplied from source $i$ to plant site at $j$

a, c Constant for estimating farmgate cost

$A P D C_{j} \quad$ Average plant delivered cost of feedstocks at site $\mathrm{j}$

$F G_{i} \quad$ Feedstock farm gate cost at source i

$P D C_{i j} \quad$ Delivered cost feedstock at plant $j$ from supply source $i$

$P P_{j} \quad$ Preprocessing cost of feedstock at site $j$

$Q_{j} \quad$ Capacity of plant at site $\mathrm{j}$

S Storage cost of feedstock

$T C_{j} \quad$ Annual cost of feedstock delivered to plant at site j 


\section{References}

[1] Perlack RD, Eaton LM, Turhollow Jr AF, Langholtz MH, Brandt CC, Downing ME, et al. US billionton update: biomass supply for a bioenergy and bioproducts industry. Oak Ridge National Laboratory (ORNL), 2011.

[2] Dale VH, Efroymson RA, Kline KL, Langholtz MH, Leiby PN, Oladosu GA, et al. Indicators for assessing socioeconomic sustainability of bioenergy systems: a short list of practical measures. Ecological Indicators. 2013;26:87-102.

[3] McBride AC, Dale VH, Baskaran LM, Downing ME, Eaton LM, Efroymson RA, et al. Indicators to support environmental sustainability of bioenergy systems. Ecological Indicators. 2011;11:1277-89.

[4] Monteleone M, Cammerino ARB, Garofalo P, Delivand MK. Straw-to-soil or straw-to-energy? An optimal trade off in a long term sustainability perspective. Applied Energy. 2015;154:891-9.

[5] Ekman A, Wallberg O, Joelsson E, Börjesson P. Possibilities for sustainable biorefineries based on agricultural residues - A case study of potential straw-based ethanol production in Sweden. Applied Energy. 2013;102:299-308.

[6] Muth Jr DJ, Bryden KM, Nelson RG. Sustainable agricultural residue removal for bioenergy: A spatially comprehensive US national assessment. Applied Energy. 2013;102:403-17.

[7] Muth Jr DJ, Bryden KM. An integrated model for assessment of sustainable agricultural residue removal limits for bioenergy systems. Environmental Modelling \& Software. 2013;39:50-69.

[8] Wilhelm WW, Johnson JM, Karlen DL, Lightle DT. Corn stover to sustain soil organic carbon further constrains biomass supply. Agron J. 2007;99:1665-7.

[9] Nelson RG. Resource assessment and removal analysis for corn stover and wheat straw in the Eastern and Midwestern United States - rainfall and wind-induced soil erosion methodology. Biomass and Bioenergy. 2002;22:349-63.

[10] Nelson RG, Walsh M, Sheehan JJ, Graham R. Methodology for estimating removable quantities of agricultural residues for bioenergy and bioproduct use. Proceedings of the Twenty-Fifth Symposium on Biotechnology for Fuels and Chemicals Held May 4-7, 2003, in Breckenridge, CO: Springer; 2004. p. 13-26.

[11] Wilhelm W, Johnson J, Hatfield J, Voorhees W, Linden D. Crop and soil productivity response to corn residue removal. Agron J. 2004;96:1-17.

[12] Wilhelm WW, Hess JR, Karlen DL, Johnson JM, Muth DJ, Baker JM, et al. Review: Balancing limiting factors \& economic drivers for sustainable Midwestern US agricultural residue feedstock supplies. Industrial Biotechnology. 2010;6:271-87.

[13] Graham RL, Nelson R, Sheehan J, Perlack RD, Wright LL. Current and Potential U.S. Corn Stover Supplies. Agron J. 2007;99:1-11.

[14] Hubbs M, Norfleet M, Lightle D. Interpreting the soil conditioning index. Making conservation tillage conventional: Building a future on. 2002;25:192-6.

[15] Karlen DL, Andrews SS, Wienhold BJ, Zobeck TM. Soil quality assessment: past, present and future. Journal of Biosciences. 2008;6:3-14. 
[16] Muth D, McCorkle D, Abodeely J, Koch J, Nelson R, Bryden K. Developing an integrated model framework for the assessment of sustainable agricultural residue removal limits for bioenergy systems. ASME 2011 International Design Engineering Technical Conferences and Computers and Information in Engineering Conference: American Society of Mechanical Engineers; 2011. p. 259-68.

[17] Muth DJ, McCorkle DS, Koch JB, Bryden KM. Modeling Sustainable Agricultural Residue Removal at the Subfield Scale. Agron J. 2012;104:970-81.

[18] Bonner IJ, Cafferty KG, Muth DJ, Jr., Tomer MD, James DE, Porter SA, et al. Opportunities for Energy Crop Production Based on Subfield Scale Distribution of Profitability. Energies. 2014;7:6509-26.

[19] de Vente J, Poesen J, Verstraeten G, Govers G, Vanmaercke M, Van Rompaey A, et al. Predicting soil erosion and sediment yield at regional scales: Where do we stand? Earth-Sci Rev. 2013;127:16-29.

[20] Guo P-T, Wu W, Sheng Q-K, Li M-F, Liu H-B, Wang Z-Y. Prediction of soil organic matter using artificial neural network and topographic indicators in hilly areas. Nutr Cycl Agroecosyst. 2013;95:33344.

[21] Licznar P, Nearing MA. Artificial neural networks of soil erosion and runoff prediction at the plot scale. CATENA. 2003;51:89-114.

[22] Wang K, Zhang CR, Li WD, Lin J, Zhang DX. Mapping soil organic matter with limited sample data using geographically weighted regression. J Spat Sci. 2014;59:91-106.

[23] Trenouth WR, Gharabaghi B. Event-based soil loss models for construction sites. J Hydrol. 2015;524:780-8.

[24] Bayram A, Kankal M, Tayfur G, Onsoy H. Prediction of suspended sediment concentration from water quality variables. Neural Comput Appl. 2014;24:1079-87.

[25] Zhang S, Huang Y, Shen C, Ye H, Du Y. Spatial prediction of soil organic matter using terrain indices and categorical variables as auxiliary information. Geoderma. 2012;171-172:35-43.

[26] Martinez A, Maier DE. Improvements in quantification of biomass feedstock availability to a biorefinery using a GIS-based method. Trans ASABE. 2014;57:533-42.

[27] Lautala P, Hilliard M, Webb E, Busch I, Richard HJ, Roni M. Opportunities and challenges in the design and analysis of biomass supply chains. Environmental Management. 2015;56:1397-415.

[28] Lourinho G, Brito P. Assessment of biomass energy potential in a region of Portugal (Alto Alentejo). Energy. 2015;81:189-201.

[29] Grassi S, Junghans S, Raubal M. Assessment of the wake effect on the energy production of onshore wind farms using GIS. Applied Energy. 2014;136:827-37.

[30] Sahoo K, Mani S. Engineering economics of Cotton Stalk supply logistics systems for bioenergy applications. Trans ASABE. 2016; 59:737-47.

[31] Delivand MK, Cammerino ARB, Garofalo P, Monteleone M. Optimal locations of bioenergy facilities, biomass spatial availability, logistics costs and GHG (greenhouse gas) emissions: a case study on electricity productions in South Italy. Journal of Cleaner Production. 2015;99:129-39.

[32] Sultana A, Kumar A. Optimal siting and size of bioenergy facilities using geographic information system. Applied Energy. 2012;94:192-201. 
[33] Höhn J, Lehtonen E, Rasi S, Rintala J. A Geographical Information System (GIS) based methodology for determination of potential biomasses and sites for biogas plants in southern Finland. Applied Energy. 2014;113:1-10.

[34] ESRI. About the ArcGIS Network Analyst extension tutorial. < http://desktop.arcgis.com/en/arcmap/ latest/extensions/network-analyst/about-the-network-analyst-tutorial-exercises.htm> [accessed may 2016].

[35] Maung TA, Gustafson CR, Saxowsky DM, Nowatzki J, Miljkovic T, Ripplinger D. The logistics of supplying single vs. multi-crop cellulosic feedstocks to a biorefinery in southeast North Dakota. Applied Energy. 2013;109:229-38.

[36] Sokhansanj S, Turholow A, Stephen J, Stumborg M, Fenton J, Mani S. Analysis of five simulated straw harvest scenarios. Can Biosys Eng. 2008;50:2.27-2.35.

[37] JMP® 11. Cary, NC, USA. SAS Institute Inc. Specialized Models. 2013.< https://www.jmp.com/ support/downloads/pdf/jmp11/Specialized_Models.pdf> [accessed may 2016].

[38] ArcGIS 10.2. Redlands, CA: Environmental Systems Research Institute (ESRI). $<$ http://desktop. arcgis.com/en/arcmap/10.3/analyze/modelbuilder/executing-tools-in-modelbuilder-tutorial.htm > [accessed may 2016].

[39] Haq Z, Easterly J. Agricultural residue availability in the United States. Applied Biochemistry and Biotechnology. 2006;129:3-21.

[40] Zhang F, Johnson DM, Sutherland JW. A GIS-based method for identifying the optimal location for a facility to convert forest biomass to biofuel. Biomass \& Bioenergy. 2011;35:3951-61.

[41] Mielenz JR. Feasibility studies for biomass-to-ethanol production facilities in Florida and Hawaii. Renewable Energy. 1997;10:279-84.

[42] Klose A, Drexl A. Facility location models for distribution system design. European Journal of Operational Research. 2005;162:4-29.

[43] Coates W. Using cotton plant residue to produce briquettes. Biomass and Bioenergy. 2000;18:201-8.

[44] Coates W. Harvesting systems for cotton plant residue. Applied engineering in agriculture. 1996;12:639-44.

[45] Milbrandt A. A geographic perspective on the current biomass resource availability in the United States. Technical Report, NREL/TP-560-39181, National Renewable Energy Laboratory (NREL); 2005.

[46] USDA-NASS (U.S. Department of Agriculture-National Agricultural Statistics Service). Quick Stats;2016.<https://quickstats.nass.usda .gov/> (accessed May 2016).

[47] USDA-NASS (U.S. Department of Agriculture-National Agricultural Statistics Service). CropScapeCropland data Layer;2016. <https: //nassgeodata.gmu.edu/CropScape/> (accessed May 2016).

[48] Revised Universal Soil Loss Equation, Version 2 (RUSLE2). Official NRCS RUSLE2 Program. Washington (DC): USDA Natural Resource Conservation Service and USDA Agricultural Research Service. <http://fargo.nserl.purdue.edu/rusle2_dataweb/RUSLE2_Index.htm> [accessed may 2016].

[49] USDA-NRCS ( U.S. Department of Agriculture-Natural Resources Conservation Service). Geospatial Data Gateway;2016. <http://datagateway.nrcs.usda.gov.> (accessed May 2016). 
[50] Zhang H, Yang Q, Li R, Liu Q, Moore D, He P, et al. Extension of a GIS procedure for calculating the RUSLE equation LS factor. Computers \& Geosciences. 2013;52:177-88.

[51] NRCS. 2012 National Resources Inventory; 2012. < http://www.nrcs.usda.gov/wps/portal/nrcs/main/ national/technical/nra/nri/>(accessed May 2016).

[52] Endale DM, Bosch DD, Potter TL, Strickland TC. Sediment loss and runoff from cropland in a southeast atlantic coastal plain landscape. Trans ASABE. 2014;57:1611-26.

[53] Georgia GIS Clearinghouse. Map Data \& Aerial Photography;2016.< https://data.georgiaspatial.org/ index.asp 2>(accessed May 2016).

[54] Sultana A, Kumar A, Harfield D. Development of agri-pellet production cost and optimum size. Bioresource Technology. 2010;101:5609-21.

[55] Shumaker GA, Luke-Morgan A, McKissick JC. The economic feasibility of using Georgia biomass for electrical energy production. Journal of Agribusiness. 2009;27:125-36.

[56] Igathinathane C, Tumuluru JS, Keshwani D, Schmer M, Archer D, Liebig M, et al. Biomass bale stack and field outlet locations assessment for efficient infield logistics. Biomass and Bioenergy. 2016;91:217-26.

[57] Langholtz M, Webb E, Preston BL, Turhollow A, Breuer N, Eaton L, et al. Climate risk management for the U.S. cellulosic biofuels supply chain. Climate Risk Management. 2014;3:96-115. 